\title{
Correction to: Characterization of a fatty acid-binding protein from the Pacific oyster (Crassostrea gigas): pharmaceutical and toxicological implications
}

\author{
Juliana F. Tisca ${ }^{1,2}$ - Karin dos Santos ${ }^{2,3}$. Tomás B. Pessati ${ }^{1,2}$. Flávia L. Zacchi ${ }^{1,2}$ • Fabíola S. Soares ${ }^{2}$. \\ Vanessa A. Oliveira $^{4}$ - Maria J. A. F. Bebianno ${ }^{5}$ - Afonso C. D. Bainy ${ }^{1,2} \cdot$ Guilherme Razzera $^{1,2,3}$ (1)
}

Published online: 19 March 2021

(C) Springer-Verlag GmbH Germany, part of Springer Nature 2021

\section{Correction to: Environmental Science and Pollution} Research

https://doi.org/10.1007/s11356-021-12645-y

The correct Fig. 3 is presented in this paper.

The original article has been corrected.

The online version of the original article can be found at https://doi.org/ 10.1007/s11356-021-12645-y

Afonso C. D. Bainy

afonso.bainy@ufsc.br

$\bowtie$ Guilherme Razzera

guilherme.razzera@ufsc.br

1 Programa de Pós-Graduação em Bioquímica, Departamento de Bioquímica, Universidade Federal de Santa Catarina,

Florianópolis, SC 88040-900, Brazil

2 Laboratório de Biomarcadores de Contaminação Aquática e Imunoquímica, Universidade Federal de Santa Catarina, Florianópolis, SC 88040-900, Brazil

3 Núcleo de Bioinformática e Biologia Computacional da UFSC-NuBioinfo, Universidade Federal de Santa Catarina, Florianópolis, SC 88040-900, Brazil

4 Centro de Biologia Molecular Estrutural, Universidade Federal de Santa Catarina, Florianópolis, SC 88040-900, Brazil

5 Centre for Marine and Environmental Research, CIMA, University of Algarve, Campus de Gambelas, 8000-139 Faro, Portugal 
a

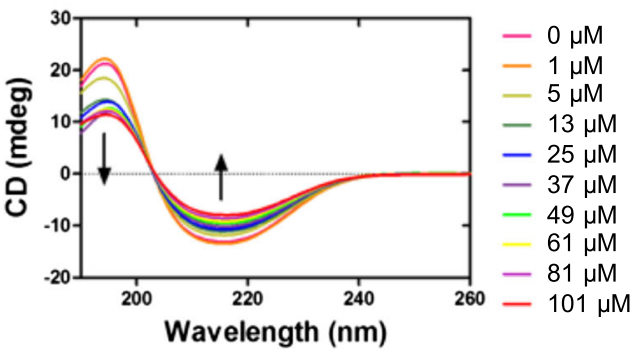

b

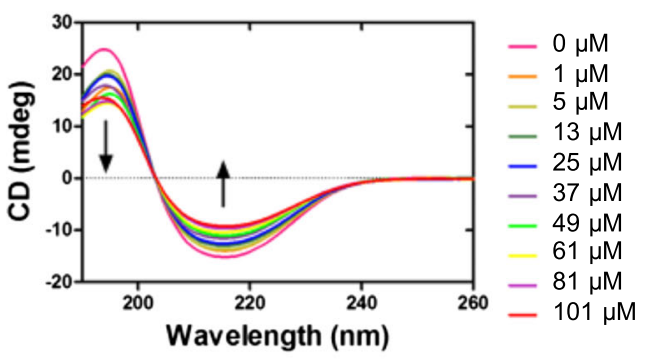

C Arachidonic acid

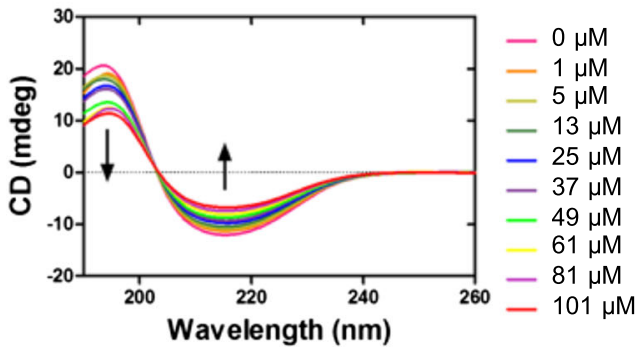

Fig. 3 Circular dichroism spectra of $\mathrm{rCgFABP} 2(5.0 \mu \mathrm{M})$ in phosphate buffer $(0.75 \mathrm{mM} \mathrm{pH} \mathrm{7.4)}$ in the presence of increasing amounts of fatty acids (a) Palmitic acid; (b) Oleic acid; and (c) Arachidonic acid. Titration stoichiometry ratios: $r=[$ ligand $] /[\mathrm{CgFABP} 2]=0.00,0.20,1.00,2.60$,

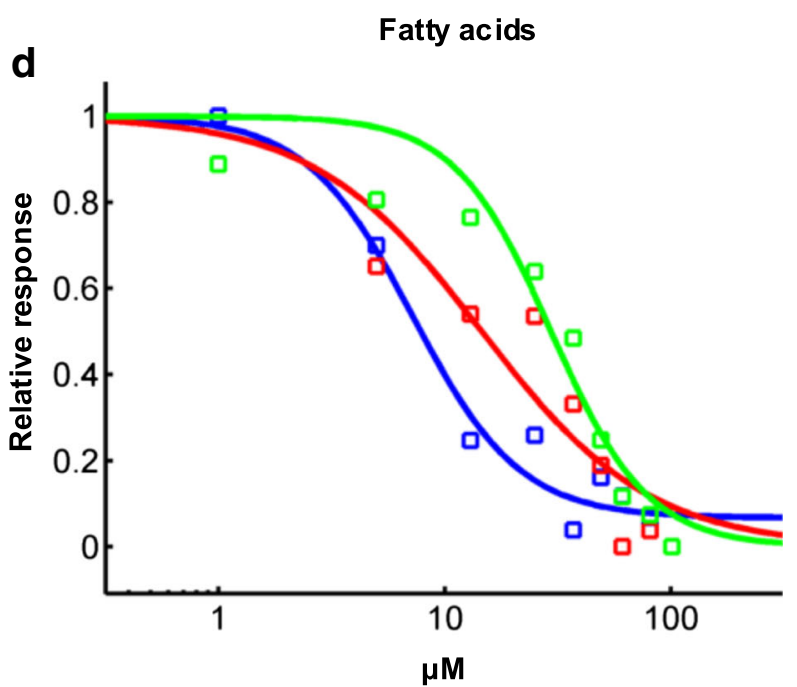

\begin{tabular}{ll} 
& Ec50 \\
\hline Palmitic Acid & $7.8 \mu \mathrm{M}$ \\
- Oleic Acid & $14.5 \mu \mathrm{M}$ \\
- Arachidonic Acid & $29.5 \mu \mathrm{M}$ \\
\hline
\end{tabular}

5.00, 7.41, 9.81, 12.21, 16.21 and 20.22. (d) The $\alpha$-helical secondary structural content at $195 \mathrm{~nm}$ as a function of ligand concentration. Halfmaximum values $\left(\mathrm{EC}^{2} 0_{1}\right)$ are shown under the curves

Publisher's note Springer Nature remains neutral with regard to jurisdictional claims in published maps and institutional affiliations. 